\title{
Analysis of the Spatial and Temporal Variation Characteristics of Ozone in the Pearl River Delta Region from 2016 to 2020
}

\author{
Huang Chuntao ${ }^{1 *}$, Lu Jifu ${ }^{1}$, Liao Qifeng ${ }^{2}$ \\ ${ }^{1}$ Huali College, Guangdong University of Technology, Guangzhou, Guangdong, 511300 \\ ${ }^{2}$ Guangdong Kedilong Technology Co., Ltd, Guangzhou, Guangdong, 510000
}

\begin{abstract}
Based on the historical data of air ozone monitoring of Pearl River Delta from 2016 to 2020, the temporal and spatial variation characteristics of ozone in the Pearl River Delta were analyzed. The results showed that the mean change curves of $\mathrm{Q}_{3}$ in the seven cities in the Pearl River Delta region from 2016 to 2020 were M-shaped, and the change trend was basically the same, except Huizhou and Zhuhai. The over standard rate of daily mean value of $\mathrm{Q}_{3}$ in Jiangmen City from 2016 to 2020 was more than $10 \%$, and the over standard situation of daily mean value of $\mathrm{Q}_{3}$ was serious. In the Pearl River Delta region, the change trend of the monthly mean value of $\mathrm{Q}_{3}$ in the same year was basically the same. On the whole, the mean value from August to November was higher, and the mean value in June was lower. The peak of Q3 concentration appeared between 12:00 and 16:00 in the daytime, and it was generally low at night.
\end{abstract}

\section{Preface}

Ozone $\left(\mathrm{Q}_{3}\right)$ is an important component of the atmosphere, about $90 \%$ of which is distributed in the stratosphere and $10 \%$ in the troposphere. $\mathrm{Q}_{3}$ in stratosphere can absorb solar short-wave ultraviolet radiation and protect all kinds of biological materials on earth. Although the content of $\mathrm{Q}_{3}$ in troposphere is small, it plays an important role in the atmospheric chemical reaction and air quality change because of its strong oxidation. In recent years, atmospheric photochemical pollution, represented by $\mathrm{Q}_{3}$ pollution, has become increasingly serious in China. Especially in summer, $\mathrm{Q}_{3}$ is the main pollutant instead of PM2.5. Higher concentration of $\mathrm{Q}_{3}$ near the ground will cause damage to human respiratory system, nervous system and eyes, especially to children ${ }^{[1]}$. In addition, $\mathrm{Q}_{3}$ can reduce crop yield and damage plant leaves ${ }^{[2]}$. Therefore, the research on $\mathrm{Q}_{3}$ pollution has become a hot spot. A lot of research work mainly focused on the relationship between $\mathrm{Q}_{3}$ and precursors [3-6], meteorological factors of $\mathrm{Q}_{3}{ }^{[7-10]}$, numerical simulation of $\mathrm{Q}_{3}{ }^{[11-12]}$, etc.

As the economic development center of Guangdong Province, the Pearl River Delta region includes nine cities in Guangdong Province, namely Guangzhou, Shenzhen, Dongguan, Foshan, Zhuhai, Huizhou, Zhongshan, Jiangmen and Zhaoqing. In recent years, the municipal governments have been actively committed to improving the ambient air quality. The haze pollution represented by PM2.5 has been effectively improved, while the $\mathrm{Q}_{3}$ pollution is becoming more and more obvious. At present, there are many studies on the relationship between the variation characteristics of $\mathrm{Q}_{3}$ in the Pearl River Delta and its precursors and influencing factors ${ }^{[13-15]}$, but few studies on the spatial and temporal distribution characteristics of $\mathrm{Q}_{3}$ in the Pearl River Delta in recent years.

Based on the historical data of air $\mathrm{Q}_{3}$ monitoring in the Pearl River Delta from 2016 to 2020, this paper studies the temporal and spatial variation characteristics of $\mathrm{Q}_{3}$ in nine cities in the Pearl River Delta, in order to provide relevant basis for the prevention and treatment of ozone pollution in the Pearl River Delta.

\section{Data resource and methods}

\subsection{Data resource}

The historical data of $\mathrm{Q}_{3-8 \mathrm{~h}}$ monitoring of the nine cities in the Pearl River Delta region from January 1, 2016 to December 31, 2020 were from the air quality historical data query network (www.aqistudy.cn/historydata). The daily and monthly mean values of $\mathrm{Q}_{3}$ in the nine cities were selected. The hourly monitoring data on June 30, 2019 and December 31, 2019 were from the website of Department of Ecology and Environment of Guangdong Province.

\subsection{Research methods and data processing}

Concerning the data of the nine cities in the Pearl River Delta used in this study, the annual mean value of $\mathrm{Q}_{3}$ was based on the monthly mean value, and the annual over standard rate of $\mathrm{Q}_{3}$ was calculated by the daily mean value

According to the Technical Regulation for Ambient Air Quality Assessment (Trial) (HJ 663-2012), Q Q $-8 \mathrm{~h}_{\text {is }}$ divided into five grades: excellent $\left(1 \sim 100 \mu \mathrm{g} . \mathrm{m}^{-3}\right)$, good 
(101 160 $\mu \mathrm{g} . \mathrm{m}^{-3}$ ), mild pollution (161 215 $\mu$ g. $\mathrm{m}^{-3}$ ), moderate pollution (216 266 $\mu$ g.m $\left.{ }^{-3}\right)$ and severe pollution and above (more than $266 \mu$ g.m ${ }^{-3}$ ). Mild pollution or above is the $\mathrm{Q}_{3}$ concentration exceeding the standard.

\section{Results and discussion}

\subsection{Annual variation characteristics of $Q_{3}$}

The variation of the annual mean value of $\mathrm{Q}_{3}$ in the Pearl River Delta from 2016 to 2020 is shown in Figure 1. The change curves of seven cities are M-shaped, except Huizhou and Zhuhai. The change trend of the seven cities is basically the same. In 2016-2017, the annual mean value of $\mathrm{Q}_{3}$ increased. In 2017-2018, the average annual value of $\mathrm{Q}_{3}$ decreases to varying degrees. In 2018-2019, the average annual value of $\mathrm{Q}_{3}$ increases, and in 20192020, the average annual value of $\mathrm{Q}_{3}$ decreases. However, the annual mean value of $\mathrm{Q}_{3}$ in Zhuhai decreases from 2016 to 2017 and then increased for two consecutive years from 2017 to 2019. The annual mean value in Huizhou City increased for three consecutive years from 2016 to 2019, and decreased from 2019 to 2020. In 2019, the annual mean value of $\mathrm{Q}_{3}$ in the Pearl River Delta region is generally higher. Zhaoqing city has the lowest annual mean value of $\mathrm{Q}_{3}$, which is 93. Dongguan, Foshan, Guangzhou, Jiangmen, Zhongshan and Zhuhai are cities with the annual mean value of more than 100 .

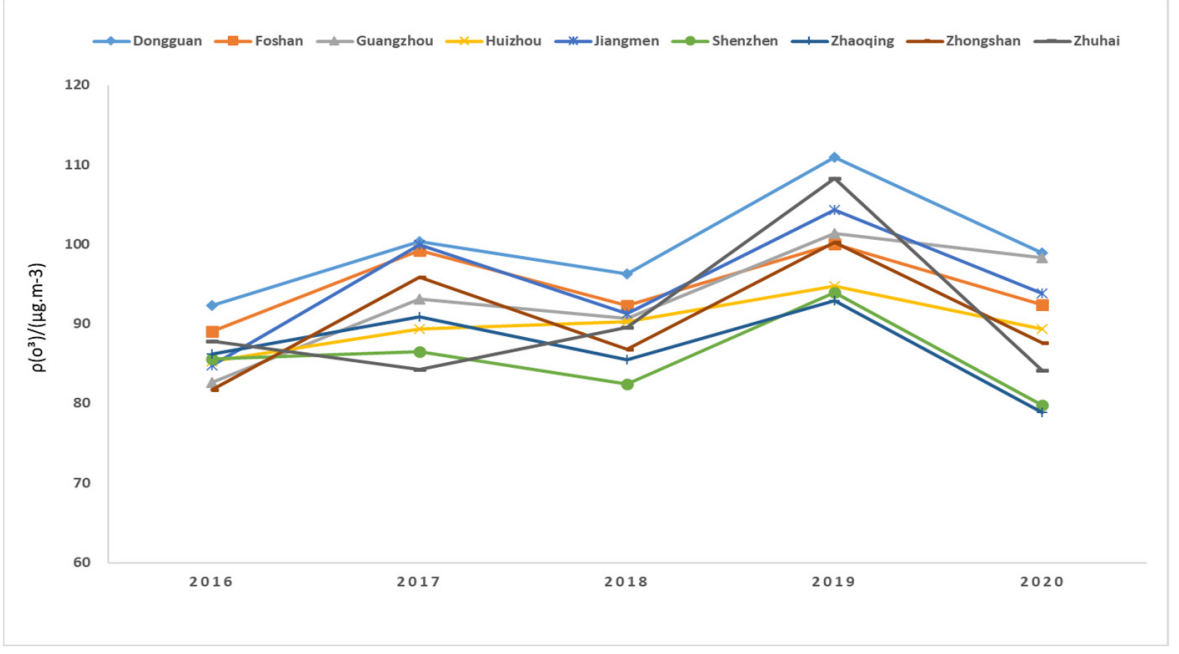

Figure 1 Variation of annual mean value of $Q_{3}$ in the Pearl River Delta region from 2016 to 2020

\subsection{Monthly variation characteristics of $Q_{3}$}

The variation of the monthly mean value of $\mathrm{Q}_{3}$ in the Pearl River Delta from 2016 to 2020 is shown in Figure 2, in which the change trend of the nine cities in the same year is basically the same. In May, July, August and September, 2016, the monthly mean value of $\mathrm{Q}_{3}$ in Pearl River Delta was higher than that from January to April. The monthly mean value of $\mathrm{Q}_{3}$ in Dongguan City in August was the highest, which was $134 \mu \mathrm{g} . \mathrm{m}^{-3}$. The variation of the monthly mean value of $\mathrm{Q}_{3}$ in the Pearl River Delta in 2017 is similar to that in 2016. The monthly mean value of $\mathrm{Q}_{3}$ in Jiangmen City in October was the highest, which was $151 \mu \mathrm{g} . \mathrm{m}^{-3}$. The variation of the monthly mean value of $\mathrm{Q}_{3}$ in 2018 is relatively gentle. The value of nine cities in October was relatively high, of which Zhuhai had the highest, $144 \mu \mathrm{g} \cdot \mathrm{m}_{-3}$. From January to July in 2019 , the monthly mean value of $\mathrm{Q}_{3}$ was low, and the minimum value in February in Foshan was $46 \mu \mathrm{g} \cdot \mathrm{m}^{-3}$. The monthly mean values from September to November were higher, and the biggest change was in Jiangmen City, and the monthly mean value in Jiangmen City in September was as high as $190 \mu \mathrm{g} \cdot \mathrm{m}^{-3}$. In 2020, the monthly mean value of $\mathrm{Q}_{3}$ in the Pearl River Delta region changed greatly, and the monthly increase and decrease were obvious. The monthly mean value of $\mathrm{Q}_{3}$ in Jiangmen City in November was the highest, $132 \mu \mathrm{g} \cdot \mathrm{m}^{-3}$.

Compared with the monthly mean values of $\mathrm{Q}_{3}$ from 2016 to 2020, the values from August to November is higher. The main reason is that the temperature is relatively high, the humidity is low, and the photochemical reaction is violent. From September to November in 2019, more cities exceeded the standard of monthly mean value of $\mathrm{Q}_{3}$. In September, Dongguan, Foshan and Jiangmen exceeded the standard. The cities with a higher monthly mean value than the standard in October are Dongguan, Jiangmen and Zhongshan, and Jiangmen and Zhongshan in November. Affected by the South China Sea monsoon climate in the southwest direction, although the temperature in the Pearl River Delta is high in June, the $\mathrm{Q}_{3}$ concentration is relatively low 


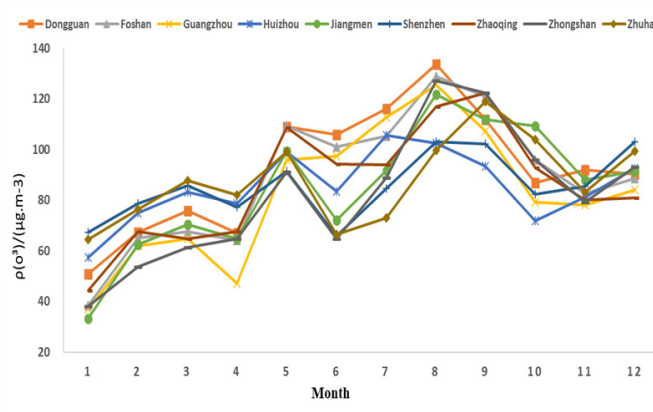

(a) 2016

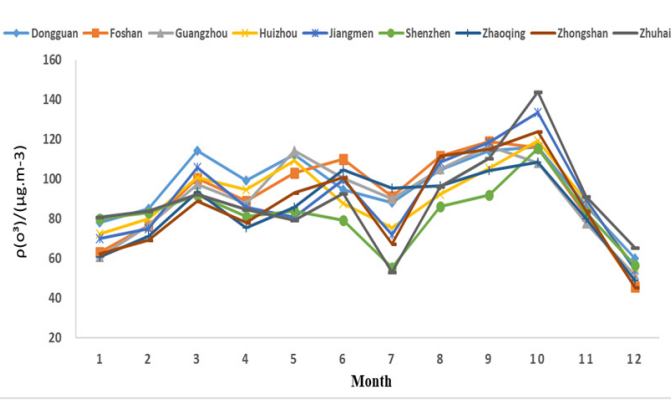

(c) 2018

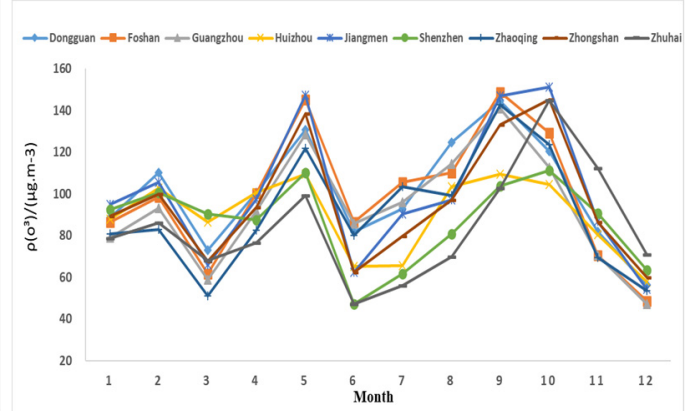

(b) 2017

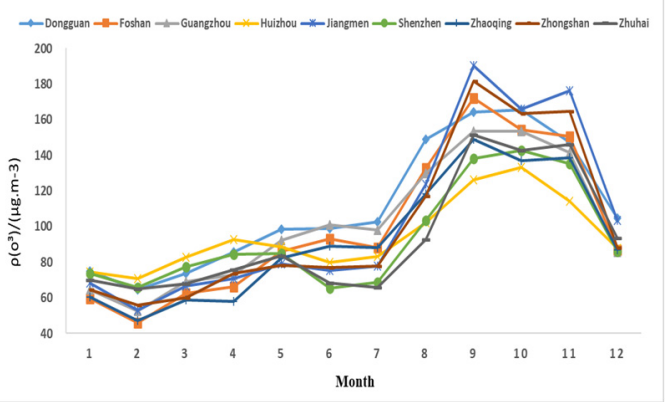

(d) 2019

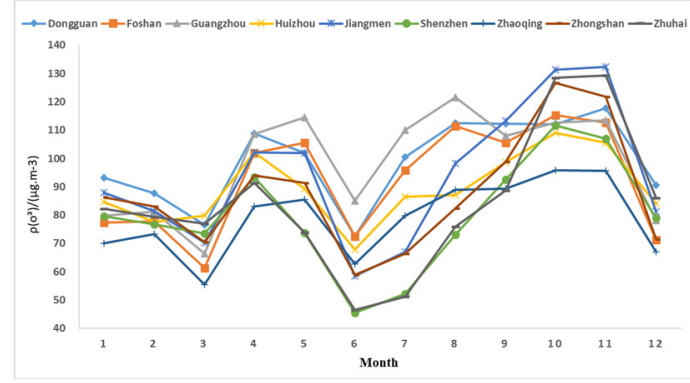

(e) 2020

Figure 2 Variation of monthly mean value of Q 3 in the Pearl River Delta region from 2016 to 2020

\subsection{Daily variation characteristics of $Q_{3}$}

The hourly variation of $\mathrm{Q}_{3}$ value in the Pearl River Delta on June 30, 2019 is shown in Figure 3. It can be seen that the variation of $\mathrm{Q}_{3}$ concentration in the Pearl River Delta region shows a typical single-peaked type. The peak of $\mathrm{Q}_{3}$ concentration appeared between 12:00 and 16:00 in the daytime, and the $\mathrm{Q}_{3}$ concentration reached $215 \mu \mathrm{g} \cdot \mathrm{m}^{-3}$ at 14:00 in Guangzhou. The photochemical reaction was weak at night, and the emission of precursors such as $\mathrm{CO}$, NOx and VOCs decreased. Therefore, the $\mathrm{Q}_{3}$ concentration was generally low at night, most of which were below $40 \mu \mathrm{g} \cdot \mathrm{m}^{-3}$. 


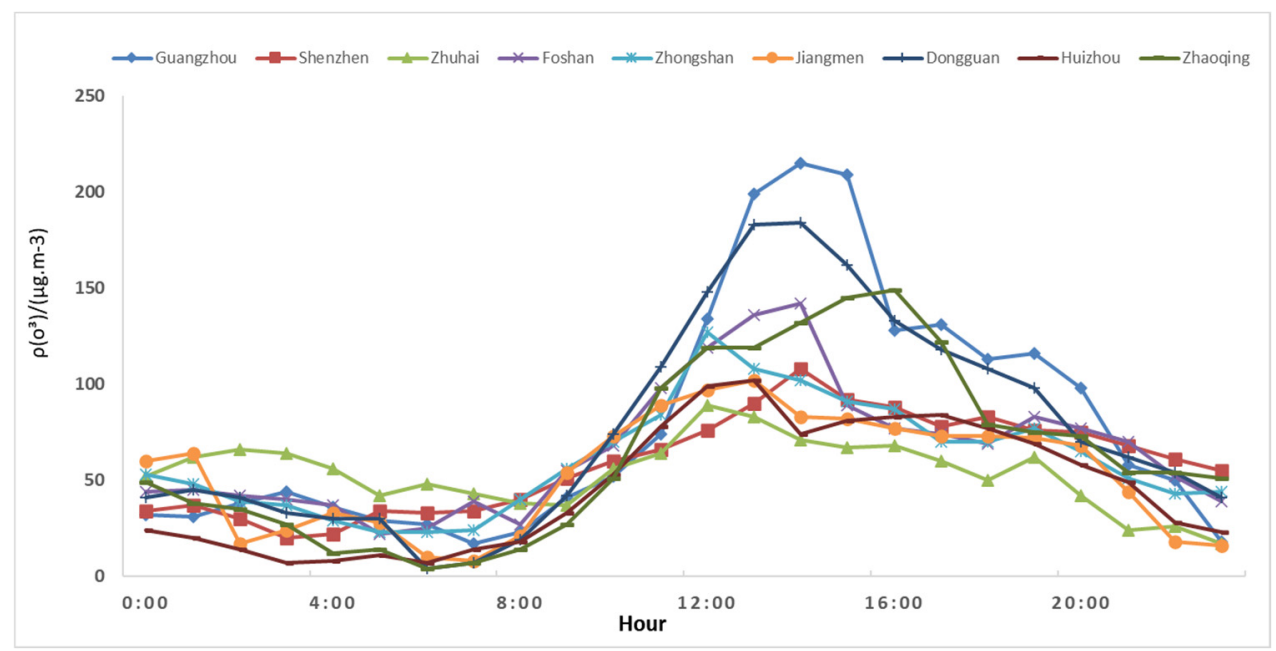

Figure 3 Variation of hourly Q3 value in the Pearl River Delta region on June 30, 2019

The hourly change of $\mathrm{Q}_{3}$ value in the Pearl River Delta on December 31, 2019 is shown in Figure 4. Most cities in the Pearl River Delta showed a typical single-peaked variation of $\mathrm{Q}_{3}$, including Guangzhou, Foshan, Zhongshan, Jiangmen, Dongguan and Zhaoqing, and the peak of $\mathrm{Q}_{3}$ concentration appeared between 14:00 and 16:00. The curve of period change of $\mathrm{Q}_{3}$ concentration in Huizhou City was M-shaped, with peak values at 7:00 and 14:00 respectively. The peak of $\mathrm{Q}_{3}$ concentration in Shenzhen and Zhuhai appeared at 22:00, which may be related to the local weather conditions.

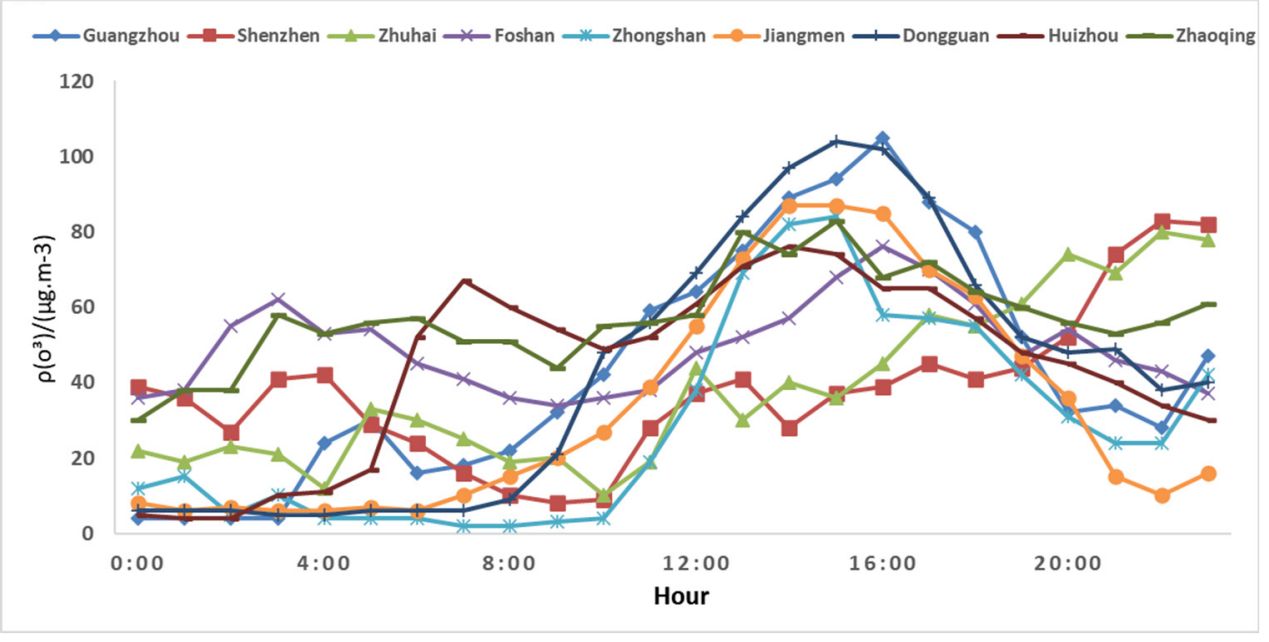

Figure 4 Variation of hourly Q3 value in the Pearl River Delta region on December 31, 2019

\subsection{Analysis of cities exceeding the standard of $Q_{3}$ concentration}

It can be seen from Table 1 that the over standard rate of daily mean value of $\mathrm{Q}_{3}$ in Jiangmen City from 2016 to 2020 is more than $10 \%$, and that of 2017 and 2019 is as high as $20.3 \%$ and $20.5 \%$ respectively. The exceedance probability of daily mean value of $\mathrm{Q}_{3}$ in Huizhou from 2016 to 2020 is below $5 \%$, and that of 2020 is only $2.2 \%$.
In 2019, the Pearl River Delta has a relatively high rate of exceeding the standard of daily mean value of $\mathrm{Q}_{3}$. The rate of Dongguan City, Foshan City, Jiangmen City, Zhongshan City and Zhuhai City is over 15\%. In 2016 and 2020 , the excellent rate of daily mean value of $\mathrm{Q}_{3}$ in the Pearl River Delta region is higher. In 2016, only Dongguan City and Jiangmen City had the excellent rate below $90 \%$, and in 2020 , there is only one city with an excellent rate below $90 \%$, namely Jiangmen City.

Table 1 Excellent rate and over standard rate of $Q_{3}$ in Pearl River Delta region from 2016 to 2020

\begin{tabular}{|c|c|c|c|c|c|c|c|c|c|c|}
\hline & \multicolumn{2}{|c|}{$\mathrm{Q}_{3}$ in 2016} & \multicolumn{2}{|c|}{$\mathrm{Q}_{3}$ in 2017} & \multicolumn{2}{|c|}{$\mathrm{Q}_{3}$ in 2018} & \multicolumn{2}{|c|}{$\mathrm{Q}_{3}$ in 2019} & \multicolumn{2}{|c|}{$\mathrm{Q}_{3}$ in 2020} \\
\hline City & $\begin{array}{l}\text { Excellent } \\
\text { rate }(\%)\end{array}$ & $\begin{array}{c}\text { Over } \\
\text { standard } \\
\text { rate }(\%)\end{array}$ & $\begin{array}{l}\text { Excellent } \\
\text { rate }(\%)\end{array}$ & $\begin{array}{c}\text { Over } \\
\text { standard } \\
\text { rate }(\%)\end{array}$ & $\begin{array}{l}\text { Excellent } \\
\text { rate }(\%)\end{array}$ & $\begin{array}{c}\text { Over } \\
\text { standard } \\
\text { rate }(\%)\end{array}$ & $\begin{array}{l}\text { Excellent } \\
\text { rate }(\%)\end{array}$ & $\begin{array}{c}\text { Over } \\
\text { standard } \\
\text { rate }(\%)\end{array}$ & $\begin{array}{l}\text { Excellent } \\
\text { rate }(\%)\end{array}$ & $\begin{array}{c}\text { Over } \\
\text { standard } \\
\text { rate }(\%)\end{array}$ \\
\hline
\end{tabular}




\begin{tabular}{|l|c|c|c|c|c|c|c|c|c|c|}
\hline Dongguan city & 88.5 & 11.5 & 84.7 & 15.3 & 91.2 & 8.8 & 80.6 & 19.5 & 91.5 & 8.5 \\
\hline Foshan city & 90.2 & 9.8 & 83.0 & 17.0 & 90.1 & 9.9 & 82.2 & 17.8 & 91.3 & 8.7 \\
\hline Guangzhou city & 91.5 & 8.5 & 86.9 & 13.1 & 90.1 & 9.9 & 85.2 & 14.8 & 90.4 & 9.6 \\
\hline Huizhou city & 97.3 & 2.7 & 95.1 & 4.9 & 96.4 & 3.6 & 95.3 & 4.7 & 97.8 & 2.2 \\
\hline Jiangmen city & 88.8 & 11.2 & 79.7 & 20.3 & 87.7 & 12.3 & 79.5 & 20.5 & 88.0 & 12.0 \\
\hline Shenzhen city & 97.0 & 3.0 & 93.2 & 6.8 & 96.4 & 3.6 & 91.0 & 9.0 & 97.3 & 2.7 \\
\hline Zhaoqing city & 91.3 & 8.7 & 88.5 & 11.5 & 93.7 & 6.3 & 89.0 & 11.0 & 97.5 & 2.5 \\
\hline Zhongshan city & 91.3 & 8.7 & 82.1 & 17.9 & 90.7 & 9.3 & 81.9 & 18.1 & 91.0 & 9.0 \\
\hline Zhuhai city & 95.4 & 4.6 & 89.9 & 10.1 & 91.5 & 8.9 & 83.4 & 16.6 & 93.2 & 6.8 \\
\hline
\end{tabular}

\section{Conclusion}

(1) From 2016 to 2020, the change curve of annual mean value of $\mathrm{Q}_{3}$ in seven cities in the Pearl River Delta region shows an M shape, except Huizhou and Zhuhai. In 2019, the annual mean value of $\mathrm{Q}_{3}$ in the Pearl River Delta region is generally high. Zhaoqing is the city with the lowest average value in $\mathrm{Q}_{3}$, which is 93. Dongguan, Foshan, Guangzhou, Jiangmen, Zhongshan and Zhuhai are cities whose annual mean value are more than 100 in $\mathrm{Q}_{3}$. The over standard rate of daily mean value of $\mathrm{Q}_{3}$ in Jiangmen City from 2016 to 2020 is more than $10 \%$, which is relatively severe.

(2) From 2016 to 2020, the change trend of annual mean value of $\mathrm{Q}_{3}$ in the nine cities in the Pearl River Delta region in the same year is basically the same. On the whole, the monthly mean value of $\mathrm{Q}_{3}$ from August to November is rather high. Influenced by the South China Sea monsoon climate in the southwest direction, although the temperature in the Pearl River Delta is high in June, the $\mathrm{Q}_{3}$ concentration is comparatively low. From September to November in 2019, more cities exceeds the monthly mean value.

(3) On June 30, 2019, the hourly variation of $Q_{3}$ in the Pearl River Delta region shows a typical single-peaked variation. The peak of $\mathrm{Q}_{3}$ concentration appears between 12:00 and 16:00 in the daytime, and it is generally low at night. On December 31, 2019, the variation of $\mathrm{Q}_{3}$ concentration in most cities in the Pearl River Delta shows a typical single-peaked change, including Guangzhou, Foshan, Zhongshan, Jiangmen, Dongguan and Zhaoqing. The variation curve of $\mathrm{Q}_{3}$ concentration in Huizhou City is $\mathrm{M}$-shaped. The peak of $\mathrm{Q}_{3}$ concentration in Shenzhen and Zhuhai appears at 22:00, which may be related to the local weather conditions.

\section{Project fund}

This paper is one of the phased achievements of the Key Discipline Cultivation Project "Civil Engineering" of Guangdong Province in 2016 (Guangdong Teaching and Research Notice [2016] No. 19) and the undergraduate teaching quality and teaching reform construction project
"Engineering Cost" of Guangdong Provincial Department of Education (Guangdong Teaching and Research Notice [2018] No. 179).

\section{References}

1. Feng, Z. Z., Li, P., Yuan, X. Y., et al. (2018) Progress in ecological and environmental effects of groundlevel O3 in China. Acta Ecologica Sinica, 38(5): 1530-1541.

2. Geng, C. M., Wang, Z. H., Ren, L. H., et al. (2014) Study on the Impact of Elevated Atmospheric Ozone on Crop Yield. Environmental Science Research, 27(3): 239-245.

3. Liu, Z., Zhu, Y. F., Guo, W. K., et al. (2019) Formation Potential of Ozone and Secondary Organic Aerosol of VOCs from Fossil Fuel Combustion in Lanzhou City. Environmental Science, 40(5): 20692077.

4. Li, G. Y., Chen Qiang, Guo Wenkai, et al. (2021) Nonlinear Response Characteristics and Control Scheme for Ozone and Its Precursors Based on Orthogon Experimental Methods. Environmental Science, 42(02): 616-623.

5. Luo, R. X., Liu, B. S., Liang, D. N., et al. (2021) Characteristics of Ozone and Source Apportionment of the Precursor VOCs in Tianjin Suburbs in Summer. Environmental Science, 42(01): 75-87.

6. Fu, Z. Q., Dai, C. H., Wang, Z. W., et al. (2019) Sensitivity Analysis of Atmospheric Ozone Formation to Its Precursors in Summer of Changsha. Environmental Chemistry, 38(3): 531-538.

7. Yang, Y. X., Chen, N. H., Hu, B. Y., et al. (2020) Characteristics of Ozone Pollution and the Influencing Factors on A Clean Island City Along the West Coast of the Taiwan Straits. Environmental Chemistry, 39(07): 1733-1743.

8. Sun, G. J., Zhu, S. D., Li, Y. N., et al. (2020) Analysis of Ozone Pollution Characteristics and Meteorological Factors in Shaoxing. Environmental Pollution and Control, 42(05): 608-613.

9. Zhou, X. S., Liao, Z. H., Wang, M., et al. (2019) Characteristics of Ozone Concentration and Its Relationship with Meteorological Factors in Zhuhai 
During 2013-2016. Journal of Environmental Sciences, 39(1): 143-153.

10. Liang, J. N., Ma, Q. X., Wang, P., et al. (2019) Analysis of the Relationship between Ozone and Meteorological Factors in Summer at Airport New City of Xixian New Area, China. Journal of Ecological Environment, 28(10): 2020-2026.

11. Wang, S., Wang, Q., Liu, M., et al. (2019) Simulation of Environmental Air Ozone Concentration and Cumulative Rate Time Series Curve in Shenyang. China Environmental Monitoring, 35(5): 26-36.

12. Hu, C.Y., Kang, P., Wu, K., et al. (2019). Study of the Spatial and Temporal Distribution of Ozone and Its Influence Factors Over Sichuan Basin Based on Generalized Additive Model. Journal of Environmental Sciences, 39(03): 809-820.

13. Liu, J., Wu, D., Fan, S.J., et al. (2017) Impacts of precursors and meteorological factors on ozone pollution in Pearl River Delta. China Environmental Science, 37(03): 813-820.

14. Shen, J., He, L., Cheng, P., et al. (2019) Characteristics of Ozone Concentration Variation in the Northern Background Site of the Pearl River Delta. Journal of Ecological Environment, 28(10): 2006-2011.

15. Chen, X. R., Wang, H.C., Lu, K.D. (2018) Simulation of organic nitrates in Pearl River Delta in 2006 and the chemical impact on ozone production. Science in China: Earth Sciences, 48(03): 366-378. 